\title{
Reflections on the role of a research task for teacher education in data handling in a Mathematical Literacy education course
}

\author{
Vera Frith and Robert Prince \\ Faculty of Higher Education Development, University of Cape Town \\ vfrith@maths.uct.ac.za and rprince@maths.uct.ac.za
}

\begin{abstract}
The introduction of the subject "Mathematical Literacy" in the Further Education and Training band from 2006 has created an urgent need for large numbers of teachers to be educated about the nature of mathematical literacy and to become effective teachers of it. In this paper we report on an attempt to contribute to this goal through a curriculum component in an "Advanced Certificate in Education" course. This curriculum component on data handling was structured around a research task which required the teachers on the course to practise mathematical literacy in a context where there is close linkage with other vital competencies, such as verbal reasoning, writing and computer literacy. This approach articulates well with the kind of teaching envisaged by the curriculum statement for "Mathematical Literacy". We report on an initial analysis of the teachers' reflections on their experience of the curriculum-embedded research task on this course, the manner in which this task contributed to their understanding of mathematical literacy as a practice and themselves as practitioners.
\end{abstract}

Note: We will use the term "Mathematical Literacy" (in quotes) to denote the school subject, and mathematical literacy, with lowercase letters, to denote the practice of mathematical (or quantitative) literacy.

\section{Introduction}

Although "Mathematical Literacy" is being introduced as a "subject" in the new South African Further Education and Training (FET) curriculum, we argue that mathematical (quantitative) literacy should be understood in the context of the social practices in which it is embedded. The term practice is used to include "both what people do and the ideas, attitudes, ideologies and values that inform what they do" (Baynham and Baker, 2002: 2). The promotion of any definition of mathematical literacy will implicitly or explicitly promote a particular social practice (Jablonka, 2003). The introduction of mathematical literacy as part of the new school curriculum has the potential to contribute to the transformation of South African schooling and society by contributing to the development of individuals' ability to participate fully and critically as citizens (National Department of Education, 2005a). One of the consequences of discriminatory educational policies in South Africa in the past is that improvements in the general quality of the mathematical literacy practices in South African society are urgently needed. We believe the new curriculum is very welcome as a means towards promoting this goal. In the medium to long term, the creation of a more mathematically literate society will contribute towards the level of mathematical, scientific and technological achievement in the country.

The introduction of the new subject of "Mathematical Literacy" necessitates the training (or retraining) of teachers to implement this complex curriculum appropriately. In the same way that a teacher's mathematical content knowledge may be the most important predictor of learning in the mathematics classroom (Kenschaft, 2005; Ball, Bass and Hill, 2004), so the development of mathematical literacy by school learners is likely to be most strongly affected by the availability of teachers who are highly mathematically literate themselves.

As part of the preparation for the implementation of the new curriculum, the four higher education institutions in the Western Cape collaborated in developing a number of different Mathematical Literacy Advanced Certificate in Education (ACE) courses for delivery in 2004. These courses were completely new and the experiences of both the teachers and the teacher educators on these courses should therefore be instructive for the design of future courses, which will no doubt be necessary. In this paper we will discuss aspects of the design and the experience of one part of one of these ACE courses. The part of the course we will focus on consisted of a brief introduction to mathematical literacy in the context of the new curriculum, followed by a detailed 
exploration of the topic of data handling. This will be referred to as the "data module" in this paper.

In this paper we will first discuss the nature of mathematical literacy and the approach which sees it as a practice within a social context. We will briefly examine the various roles played by an inservice teacher learning to teach the unfamiliar curriculum for "Mathematical Literacy". We will then outline the design of the "data module" of the ACE course in the light of these ideas. We will describe the role of a research task in developing the teachers' mathematical literacy practice. In order to discuss the contribution of the research task to this development, we examine the teachers' written reflections on their experience of the task. This is an initial investigation that is part of a larger, more long-term research programme investigating aspects of teacher education for mathematical literacy.

\section{Mathematical literacy as contextualised practice}

This paper argues for an approach to mathematical literacy (and other literacies) which sees them as practices embedded in particular social contexts (Archer, Frith and Prince, 2002). Baker, Clay and Fox (1996: 3) refer to "the collection of numeracy practices that people engage in - that is the contexts, power relations and activities - when they are doing mathematics." Mathematical literacy should not be seen as only a set of identifiable mathematical skills that can be learnt without reference to the social contexts where they might be applied.

According to Jablonka (2003: 78), “Any attempt at defining mathematical literacy faces the problem that it cannot be conceptualised exclusively in terms of mathematical knowledge, because it is about an individual's capacity to use and apply this knowledge. Thus it has to be conceived of in functional terms as applicable to the situations in which the knowledge is to be used." This emphasis on the use and application of knowledge implicitly assumes the importance of the associated quantitative thinking and reasoning.

We take the view that mathematical literacy events can be described in terms of the contexts, the mathematical and statistical content and the underlying reasoning and behaviours that are called upon to respond to a situation that requires mathematical literacy practice. There is a subtle but important difference between this view, which sees mathematical literacy as a practice, and the view expressed in the South African National Curriculum Statement Grades 10-12 (General)
Mathematical Literacy (National Department of Education, 2003: 9), which defines mathematical literacy as a "subject". However, the emphasis on problem solving in real contexts is fundamental to both definitions.

The debate about the meaning of the term 'mathematical literacy' (also known as 'numeracy' or 'quantitative literacy' in different countries) and its relationship to 'literacy' and to 'mathematics' is exemplified by the various articles in the book Mathematics and Democracy: The Case for Quantitative Literacy (Steen, 2001). The articles in this book reinforce the idea that mathematically literate practice, as opposed to mathematics, is always embedded within a context. Hughes-Hallett (2001:94) summarises the difference between mathematical (quantitative) literacy and mathematics as follows: "Mathematics is about general principles that can be applied in a range of contexts; quantitative literacy is about seeing every context through a quantitative lens".

In thinking about 'context', Usiskin (2001) warns against the use of contrived 'real-life' examples masquerading as 'reality' in the mathematics classroom. Teaching "Mathematical Literacy" requires the use of contexts which are real for those involved, and which need to be understood as clearly as the mathematics that is being applied.

Very often mathematical literacy events (the situations where mathematical literacy is practised) require the content, contexts and reasoning that are usually associated with the use of statistics (Hughes-Hallett, 2001). Thus data handling is arguably the most important component in the "Mathematical Literacy" curriculum and one which distinguishes it from what is being called the core "Mathematics" curriculum (National Department of Education, 2005b).

We adopt the following definition of mathematical literacy, in which all three approaches to the description (contexts, content and reasoning) are embedded:

Mathematical literacy is the ability to manage situations or solve problems in practice, and involves responding to quantitative (mathematical and statistical) information that may be presented verbally, graphically, in tabular or symbolic form; it requires the activation of a range of enabling knowledge, behaviours and processes and it can be observed when it is expressed in the form of a communication, in written, oral or visual mode. 


\section{Reflections on the role of a research task for teacher education in data handling \\ in a Mathematical Literacy education course}

This definition has been informed by the discussions and definitions implicit in the frameworks used by the TIMMS (Mullis et al., 2003), PISA (Programme for International Student Assessment, 2003) and ALL (Adult Literacy and Lifeskills, 2002) studies, but it draws most heavily on the latter.

The definition of mathematical literacy which we have adopted implies that being mathematically literate requires the ability to express quantitative information coherently in a verbal and visual form. Kemp (1995) argues that mathematical literacy includes the ability to communicate clearly and fluently and to think critically and logically. In dealing with quantitative or mathematical ideas in context, students should be able to interpret information presented either verbally, graphically, in tabular or symbolic form, and be able to make transformations between these different representations. The transformation of quantitative ideas into verbal messages is the area where a student's ability to write coherently about quantitative ideas will be exercised. Mathematical literacy also requires the ability to choose the appropriate form for the expression of a quantitative idea, and to produce a text that expresses that idea. Thus the practice of mathematical literacy must include the ability to put together a document for a particular purpose in a particular context.

\section{The teacher as learner in the ACE course}

Just as mathematical literacy as a domain can be usefully conceptualised as a social practice, so has learning itself been extensively described using a social practice perspective (Lave and Wenger, 1991; Wenger, 1998). In particular this approach has been found useful for investigating teacher learning (Graven, 2004; 2005). Thinking of teacher learning as taking place within a community of practice, throws the focus strongly onto the teacher's sense of identity and the changes in this identity that the educational programme brings about. Graven (2004) also highlights the central role played by the learner teacher's confidence. By examining the teachers' reflections on their experience we also emphasise the importance of these factors.

We have argued that mathematical literacy can be thought of as a practice within a social context. Similarly mathematical literacy as experienced by the learners in educational interventions will be a different but related practice, which with careful management by the educator, could be closely enough related to the practices in broader society to allow for significant transfer of practices into the world outside of the educational setting. This transfer is facilitated by educational practices that mirror the mathematical literacy practices of society as closely as possible and assignments where learners will be required to practise mathematical literacy outside of the educational context. This is one of the reasons why, for example, a research task such as the one described in this paper is so important.

Although we are focusing in this paper on the development of the teachers' mathematical literacy practices themselves, it is worth pointing out that the teachers were on the ACE course to develop their own mathematical literacy practices and to learn how to teach the subject "Mathematical Literacy". In both cases they were subject to the dichotomy between classroom and "real-world" practices, and the corresponding confusion of identities. So not only were they hoping to transfer their own mathematical literacy practices from the ACE classroom to their lives as citizens, as professionals and as "Mathematical Literacy" teachers in particular, but they were also hoping to transfer learning about the practice of teaching from the ACE classroom to their own work practice in school. The teachers in the ACE classroom were expected to maintain a dual identity as learners and as reflective teachers contemplating implementing a new curriculum, but without the opportunity to do so until after the course was completed. Their identity as learners was further complicated by the fact that they are in practice already teachers, but not of "Mathematical Literacy". So in a sense they were experiencing inservice teacher education and in another sense it was pre-service education, given that the new curriculum had not yet been implemented in the schools.

So in engaging with the research task in the course, the teachers had to play and/or reflect upon various roles (identities). For example, in doing the research task they were themselves learners within the context of the course, but were also modelling the school learners they would be teaching in the future, by carrying out an assignment identical to one that might be expected of grade 10 or 11 learners. At the same time as developing their own mathematical literacy, they were expected to reflect upon their role as teachers in the classroom, both in their current practice and in their future practice as "Mathematical Literacy" teachers. 


\section{The "Data module" of the Mathematical Literacy ACE course}

The part-time Mathematical Literacy ACE course, which lasted for two years, consisted of five modules, each lasting for the equivalent of one semester (about 14 weeks). Four of the modules were devoted to the "Learning Outcomes" of the school "Mathematical Literacy" curriculum. Thus there was one module on "data handling", one on "numbers and operations", one on "functions and algebra" and one on "space and shape". The teaching and assessment of the material for the fifth module, which was on "curriculum and assessment", was integrated throughout the four other modules. The students on the course, who were practicing teachers, were required to attend scheduled three-hour classes once a week. There were also additional classes and computer laboratory sessions for those needing extra assistance. Students were also expected to do homework and complete assignments for assessment in their own time. There was a final written examination for each of the four modules that were based on the "Mathematical Literacy" curriculum learning outcomes.

The first semester of the ACE course was devoted to data handling (which we call the "data module" for convenience). The mathematical and statistical content for this course was the analysis, representation and interpretation of data. For the design of the data module we drew upon our experience in designing curricula for and teaching on quantitative (mathematical) literacy courses for first year university students on a variety of study programmes (Archer, Frith and Prince, 2002; Frith, Jaftha and Prince, 2005). The principles that guided our curriculum design (consistent with seeing mathematical literacy as contextualised social practice) were:

- that material should be context-based and make use of real relevant intrinsically motivating contexts, wherever possible;

- that curriculum tasks should require the exercise of several related competencies, such as writing and using computers, not just mathematical skills;

- that the production of a (mainly verbal) product as an outcome of mathematically literate practice is important (as well as the understanding and interpretation of existing information);

- that students' confidence should be promoted;
- that co-operative learning should be emphasised.

The 14 three-hour classroom sessions were run as workshops with limited presentation of course content at the blackboard. Students worked in groups and engaged with the course materials while lecturers acted as facilitators. Some sessions were conducted entirely in the computer laboratory so that students could develop proficiency in using a spreadsheet program. The first three sessions provided an initial orientation to the nature of mathematical literacy and to the Subject Statement and Assessment Standards for the subject "Mathematical Literacy". The rest of the first semester was devoted to the study of Learning Outcome 4: Data Handling from the Subject Statement (National Department of Education, 2003).

At the beginning of the course the 33 teachers (of whom 29 completed the ACE course successfully) wrote an extensive pre-test, designed to assess their mathematical literacy and reveal areas of strength and weakness. The use of this test for similar purposes was described by Prince and McAuliffe (2005). For those students whose results on this test indicated the need for additional instruction in specific mathematical and statistical concepts, extra workshops were provided. These workshops were intended to provide these teachers with a sense of competence and confidence to play an active and constructive role in the main classroom sessions. For this module formative assessments were used and a summative assessment (final examination) was written at the end.

\section{The Research task in the data module}

Structuring the curriculum of the "data module" around the execution of an independent research task provided an ideal environment for the development of the teachers' mathematical literacy practice by realising the curriculum design principles outlined above. A research task of this nature is a mathematical literacy event which has many affordances, such as enriching the understanding of sampling, bias and uncertainty, developing data handling techniques, use of language and technology, and promoting quantitative reasoning. Similar affordances provided by graphical representations are explored in Prince and Archer (2005). It was assumed that by learning about data handling within the context of completing an authentic task, the relevance of the curriculum content was demonstrated and the motivation of learners was promoted. It also allows 


\section{Reflections on the role of a research task for teacher education in data handling \\ in a Mathematical Literacy education course}

for the various literacies (for example, writing and use of technology in the form of calculators and spreadsheet applications) to be used in a way that is less contrived and closer to a 'real-world' experience.

Although the research task was done by the teachers individually mostly in their own time, the course provided extensive scaffolding exercises and opportunities for cooperative work with other students. The task was identical to one presented using a similar curriculum structure in a grade 10 textbook (Bowie, Frith, Prince and Schauerte, 2005) and similar to the research task in the companion grade 11 text book (Bowie, Frith and Prince, 2006). The task was presented at the beginning of the data module and students were informed that they would be expected to work consistently on the execution of the task, in step with the scaffolding provided throughout the course. An extract from the statement for the research task is shown in figure 1 .

\section{Research task}

For this project you will work on your own and do your own survey. In this chapter you have seen two examples of the kind of survey you should do. All the steps that you have to do to complete a survey are covered in the units in this chapter.

\section{Suggested example of a survey:}

Purpose:

To find out about young people's attitudes towards living in South Africa.

Questions:

- Age, gender, grade at school, etc.

- How positive do they feel about their future in South Africa?

- How important do they think it is to vote in an election?

- Do they think South Africa has a lot to offer young people?

- How proud are they to be South African?

- How important is it to them that South African sportsmen and women should win in international competitions (such as the Olympics)?

Figure 1: Abridged extract from a grade 10 textbook presenting the "research task"

Teachers were also free to devise their own research questions, relating to aspects of the lives of the school learners they were currently teaching. For example, one teacher researched learners' living conditions and another researched learners' attitudes towards nutrition and exercise.
The scaffolding exercises were structured to provide support in parallel with the execution of this task, in a similar manner to the way support was provided in the textbook. We believe that it is more effective to provide scaffolding as the task unfolds (rather than before it is attempted), as transfer of knowledge is more likely to take place if the connections are made more explicit in this way. For example, the first session provided a framework for understanding the research process as a whole, while during the second session students worked together to pilot and refine their survey questions for the project. At this stage they were expected to conduct their survey and gather their data. During sessions two to seven, students were expected to reflect on the relevance to their research of the techniques for data analysis and representation covered in the workshop sessions, and to apply these techniques to their own data (including the use of spreadsheets). At the same time they were told that they should be working on writing up their report. In the ninth session they were assisted by a language expert (a lecturer from the Language Development Unit at the University) to peer-edit each other's writing and to provide constructive criticism, before revising their draft reports for final submission at the end of the data module.

In structuring the "data module" this way, the intention was to provide as authentic as possible an opportunity to experience and become more expert in mathematical literacy practice. The intention of the research task was that the teachers would:

- Become proficient at analysis, representation and interpretation of data.

- Develop an appreciation for the processes that comprise quantitative research and the manner in which they could influence the research results.

- Recognise through experience the importance of using relevant contexts as a vehicle for learning "Mathematical Literacy".

- Work cooperatively with peers and other educators.

- Communicate their findings effectively in the form of a written report.

- Reflect on the implications of their experiences for their mathematical literacy practice.

\section{The Reflection task in the data module}

For the discussion of the effectiveness of the research task in achieving the intentions listed 
above, in this paper we will focus on the teachers' reflections on their experience of this task.

As part of the research task ("project") statement, students were also asked to reflect on their experience of the process of completing the task. To assist them to structure their thoughts, they were given the following guiding questions (which are also part of the "project" task in the school learners' textbook referred to above):

- Which part of the project did you find the easiest to do?

- Which part was the hardest?

- What would you do differently next time?

- Is there any part of the process of doing a survey that you will need to get help with before you do a similar survey again?

- Did you enjoy doing the project? Explain why or why not.

- Describe the main thing that you think you learned from doing this project.

Of the 33 teachers on the course, 29 included written reflections with their project submission.

\section{Teachers' reflections on the research task (the "project")}

Parts of the "project" teachers found easiest: Most teachers said that the easiest part of the project was the actual collection of the data by administering their questionnaire to the learners at their school. Some cited the choice of research question as the easiest aspect and several others found the mechanical processes of data analysis (such as drawing up frequency tables or calculating statistics) the easiest part.

Parts of the "project" teachers found difficult:

More than half the teachers described their difficulty in designing the questionnaire for their survey. Comments like the following were fairly common: "(The hardest part was) setting and changing the questions to the questionnaire to make it appropriate for my survey's statement and to minimize ambiguity."

Many teachers also reflected on the difficulties they had experienced with the analysis and interpretation of their data. In some cases they were aware of difficulties in deciding which kinds of analysis and representations to use, or difficulties in actually performing this analysis: "The analysis of the data was difficult for me as I was not always sure which tools to use to present the data and if the choices I made was the appropriate ones."

About one third of the teachers reflected specifically on their difficulty with the writing of the report and the kinds of reasoning that this required. The following is typical: "The analyzing and the reporting of the findings were difficult as this needed a reflection on the data provided and to comment on what was evident there. The writing of the report was also difficult because it needed an unbiased opinion and the facts stated had to be always based on the information provided."

\section{Parts of the "project" teachers would do} differently:

The most frequent observations under this heading were to do with improving the questionnaire design and changing the size and nature of the sample, either to make the task more manageable or to improve the quality of the information obtained. Several teachers also commented on the need for better planning and time management, particularly to allow for more input from and interaction with peers. Some mentioned the need for a more unified approach to the whole research process and others observed that they would use a spreadsheet for their data analysis.

The following quotes highlight some of these issues: "Based on my question, I would get an idea of what it is that I would like to discuss in the report and ensure that the questionnaire provides me with information to be able to do this. In this way each part of the activity is not seen as isolated or independent of the other, because the questionnaire is eventually going to impact on what you are able to write about in the report." And, "The second (thing I would do differently) is to get constant feedback from fellow class mates so that I can face the next task with more confidence."

\section{Parts of the process where teachers would need} more help:

Most teachers who responded to this question said that they would need help with the questionnaire design and/or the writing of the report. Thus it appears that they are least confident about the ability to communicate quantitative ideas in writing. A few teachers also indicated a lack of confidence in their ability to analyse and present their data graphically in an appropriate way. A few students identified the need to improve their ability to interpret the data: "(I would need more help with the stage where) you have collected the data and need to make statements about the findings. The session on writing the report focused on the 


\section{Reflections on the role of a research task for teacher education in data handling \\ in a Mathematical Literacy education course}

actual writing of the interpretations. How to make those necessary interpretations is important and needs more developing."

Teachers' enjoyment of the task:

More than two thirds of the teachers said that they had enjoyed the research task, in spite of some having reservations about time pressure and anxiety about whether they "were on the right track". The following quotes illustrate how the context of the learning task can influence the affective reaction to it: "I did enjoy doing the survey. The challenge of designing an applicable questionnaire was exhilarating. Seeing the results emerging, analyzing it, seeing a pattern in the learners' responses and then writing up the results kept me curious." And "... I feel a sense of achievement. I started something which I took control of fully and have completed it to the best of my ability."

\section{Teachers' opinions about the main things they learnt from doing the project:}

Teachers mentioned a large variety of topics under this heading, such as report writing, data analysis techniques, questionnaire design and the value of collaboration, for example: "I learned mostly how to work with people including learners and my fellow students and lecturers." However, the most frequently mentioned topics were to do with an appreciation of the processes that research entails, and/or the need for planning and time management, for instance, "I now have a fairly good idea of what research entails. I actually collected the raw data which we only see in books. We started a process at the very beginning, processed the data and carried the process through to the end."

It is telling that for some teachers the most significant learning was not about data handling or the research process, but arose from the context of the research itself. These teachers cited as most important insights they had gained about their school learners, which arose either from their actual research results or from the experience of their engagement with the research task. Reflections like the following illustrate how relevant the research task was to the teachers' real working environments: "I learned to be more tolerant and patient towards the learners. I now consciously listen to their reasons for absenteeism"; "Young people are extremely willing to be co-operative and helpful. They are enthusiastic to help adults on condition that their assistance is acknowledged and they don't feel exploited."

\section{Discussion}

We discuss the teachers reflections in the light of each of the stated intentions of structuring the data module around the execution of a research task. These intentions were listed above at the end of the section under the heading "The Research task in the data module".

Becoming proficient in the analysis, representation and interpretation of data:

Although the analysis and interpretation of data was a major component of the material covered in the classroom sessions and some teachers cited it as the easiest aspect of the project, there were still many teachers who reflected on the difficulties they had experienced with the analysis and representation of their data. Other teachers commented not so much on the data analysis as on their difficulties with the more subtle task of deriving meaningful quantitative information from their representations of the data.

These difficulties reveal a worrying lack of competence with tasks which are fundamental to the achievement of Learning Outcome 4 Data Handling (National Department of Education, 2003), but which cannot be assumed to be common knowledge even for a person with a reasonable level of mathematical education. This points to the need for extensive training of teachers in data handling and interpretation, especially as this is a new component in the Mathematics curriculum as well.

Developing an appreciation for the processes that comprise quantitative research and the manner in which they could influence the research results:

A number of students discussed their growing awareness of the interdependence of the components of the research process. In grappling with their difficulties with questionnaire design, they developed an awareness of the impact of the research instrument and method on the quality of the data that could be collected, and hence the conclusions that could be drawn. This kind of insight is valuable both for their own development as mathematically literate practitioners, and for making them more able to promote critical thinking about data in the classroom (which is heavily emphasised in the "Mathematical Literacy" FET curriculum). An appreciation for the dependence of the quality of the data and the conclusions drawn from it on the research 
processes (such as possible bias in sampling) is one of the learning outcomes, which we believe is best learned in practice.

When they reflected upon the research process, in terms of their own engagement with it, one of the strongest themes to emerge was to do with time management. Teachers developed an appreciation for the importance of drafting and redrafting questions and text using input from other people: "... my concern was the process that I had to follow. But when I started interacting with my fellow colleagues, the whole picture became more clear. I started rephrasing my research questions, and once this was done, working through the process step by step became easier. The lectures on analytical and graphical presentations of data added more clarity. Hence the knowledge that I gained in class helped me further to develop my understanding of my own research project."

The teachers' reflections on the process make it very clear that they feel that it takes considerable time to communicate with peers and to assimilate and practise applying the new competencies learnt in the course. The reflections generally create the impression that the research task was an effective vehicle for this, although even more time would have been appreciated. The implication of this is that "crash courses" for "Mathematical Literacy" teachers will probably be less effective at developing teachers' mathematically literate practice.

Recognising through experience the importance of using relevant contexts as a vehicle for learning "Mathematical Literacy":

Most of the teachers reported having enjoyed the research task. One of the intrinsically motivating factors was their interest in the information they were gathering itself. So for these teachers the task had intrinsic value, not just as an assignment for the course, but as a task that illuminated and enriched their teaching experience. Some teachers also made statements that revealed that completing the research task gave them a sense of worth and an identity as a researcher. These experiences highlight the power of using real, relevant and intrinsically interesting contexts as a vehicle for developing mathematical literacy and promoting learners' confidence.

\section{Working cooperatively with peers and other educators:}

Just under half the teachers made some comment reflecting their appreciation of the value of collaborative work with other teachers (and in some cases their own school learners) and of gaining input from the lecturers during the research process. "Peer assessments of our projects helped a lot, because you can make the changes as you go along. Other people's different perspectives allows you to broaden your own perspective and enriches yourself to complete a project with success." In our opinion, this aspect of their experience of doing the research task may be one of the most valuable in terms of preparing them to be effective facilitators of learning in the "Mathematical Literacy" classroom, where they will be expected to motivate school learners to work collaboratively and to facilitate this kind of learning.

\section{Communicating findings effectively in the form of a} written report:

More than half the teachers described their difficulty in designing the questionnaire for their survey. This highlights the importance of the "literacy" component of mathematical literacy. About one third of the teachers reflected specifically on their difficulty with the writing of the report and the kinds of reasoning that this required. The general level of difficulty experienced in writing about data was also reflected in the quality of the reports, which indicated that teachers were probably not adequately prepared to support school learners with this kind of writing task, which is a fundamental component of "Mathematical Literacy". Further research will focus on the insights that can be derived from a close study of the actual research reports submitted.

\section{Conclusion}

In designing a curriculum for "Mathematical Literacy" teacher training, it is useful to frame mathematical literacy as contextualised social practice. Some of the implications of this framework for the curriculum are that mathematical and statistical content should be taught through learners' engagement with realistic, relevant contexts; that critical thinking and communication are important elements and that collaborative work should be encouraged. The development of positive attitudes and confidence should also be promoted. We maintain that structuring the curriculum of the data handling component of a "Mathematical Literacy" course (for teachers or for school learners) around the execution of a scaffolded research task provides an effective environment for the realisation of these principles. This view is supported by the results of our analysis of the reflections written by the 


\section{Reflections on the role of a research task for teacher education in data handling in a Mathematical Literacy education course}

teachers about the research task in the "data module" of the Mathematical Literacy Advanced Certificate in Education course.

\section{Acknowledgement}

We are very grateful to our late colleague, Stella Clarke, who assisted us with facilitating the writing component of the research task, reported in this paper, at a difficult time in her life. We are also grateful for the insights and inspiration we have received from her.

\section{References}

ALL. (2002). Adult Literacy and Lifeskills Survey. Numeracy - Working Draft. Retrieved March 24, 2003, from http://www.ets.org/all/numeracy.pdf

Archer, A., Frith, V., \& Prince, R.N. (2002). A Project-based Approach to Numeracy Practices at University Focusing on HIV/AIDS. Literacy and Numeracy Studies, 11(2), 123-131.

Baker, D., Clay, J., \& Fox, C., (Eds.). (1996). Challenging Ways of Knowing. In English, Maths and Science. London and Bristol: Falmer Press.

Ball, D.L., Bass, H., \& Hill, H.C. (2004). Knowing and using Mathematical Knowledge in Teaching: Learning what Matters. In A. Buffler \& R.C. Laugksch (Eds.), Proceedings of the $12^{\text {th }}$ Annual Conference of the Southern African Association for Research in Mathematics, Science and Technology Education (pp. 51-65). Durban: SAARMSTE.

Baynham, M., \& Baker, D. (2002). "Practice" in Literacy and Numeracy Research: multiple perspectives. Ways of Knowing Journal, 2(1), 1-9.

Bowie, L., Frith, V., Prince, R., \& Schauerte, A. (2005). Focus on Mathematical Literacy Grade 10 Learner Book. Cape Town: Maskew Miller Longman.

Bowie, L., Frith, V., \& Prince, R. (2006). Focus on Mathematical Literacy Grade 11 Learner Book. Cape Town: Maskew Miller Longman.

Frith, V., Jaftha, J.J., and Prince, R.N. (2005). Interactive Excel Tutorials in a Quantitative Literacy Course for Humanities Students. In M.O. Thirunarayanan, Aixa Pérez-Prado (Eds.), Integrating Technology in Higher
Education (pp. 247-258). Maryland: University Press of America.

Graven, M. (2004). Investigating mathematics teacher learning within an in-service community of practice: the centrality of confidence. Educational Studies in Mathematics 57, 177-211.

Graven, M. (2005). Mathematics teacher retention and the role of Identity: Sam's story. Pythagoras 61(June), 2-10.

Hughes-Hallett, D. (2001). Achieving Numeracy: The Challenge of Implementation. In L.A. Steen (Ed.), Mathematics and Democracy, The Case for Quantitative Literacy (pp. 9398). USA: The National Council on Education and the Disciplines.

Jablonka, E. (2003). Mathematical Literacy. In: A.J. Bishop, M.A. Clements, C. Keitel, J. Kilpatrick, \& F.K.S. Leung, (Eds.), Second International Handbook of Mathematics Education (pp. 75-102). The Netherlands, Dordrecht: Kluwer Academic Publishers.

Kemp, M. (1995). Numeracy across the tertiary curriculum. In R.P. Hunting, G.E Fitzsimmons, P.C. Clarkson, and Alan J. Bishop (Eds.), International Commission on Mathematics Instruction Conference on Regional Collaboration (pp. 375-382). Melbourne: Monash University.

Kenschaft, P.C. (2005). Racial equity requires teaching elementary school teachers more mathematics. Notices of the American Mathematical Society 52(2), 208-212.

Lave, J., \& Wenger, E. (1991). Situated learning: Legitimate peripheral participation. New York: Cambridge University Press

Mullis, I.V.S., Martin, M.0., Smith, T.A., Garden, R.A., Gregory, K.D., Gonzalez, E.J., Chrostowski, S.J., \& O'Connor, K.M. (2003). TIMSS (Trends in Mathematics and Science Study) Assessment Frameworks and Specifications 2003. (2nd Edition). International Association for the Evaluation of Educational Achievement and International Study Center, Lynch School of Education, Boston College, US. Retrieved February 10, 2005, 
http://timss.bc.edu/timss2003i/PDF/t03_af_bo ok.pdf

National Department of Education (NDE). (2003). National Curriculum Statement Grades 10-12 (General.) Mathematical Literacy. Department of Education, South Africa. Retrieved February 28, 2005, from http://www.education.gov.za/content/documen ts/111.pdf

National Department of Education (NDE). (2005a). National Curriculum Statement Grades 10-12 (General). Learning Programme Guidelines - Mathematical Literacy. Department of Education, South Africa. Retrieved February 28, 2005, from http://www.education.gov.za/content/documen ts/737.pdf

National Department of Education (NDE). (2005b). Subject Assessment Guidelines Mathematics, Department of Education, South Africa. Retrieved February 28, 2005, from http://www.education.gov.za/content/documen ts/755.pdf

Prince, R.N., \& McAuliffe, S. (2005). Can Numeracy Levels of first year education students help inform programme design? Presented at: First African Regional Congress of the International Commission on Mathematical Instruction (ICMI) 22-25 June
2005. University of the Witwatersrand, South Africa.

Prince, R.N., \& Archer, A.H. (2005). Quantitative Literacy as Situated Social Practice in Higher Education. International Journal of Learning, 12(7), 227-234.

Programme for International Student Assessment. (2003). The PISA 2003 Assessment Framework - Mathematics, reading, science and problem solving knowledge and skills. Organisation for Economic Co-operation and Development (OECD). Retrieved February 10, 2005, from http://www.pisa.oecd.org/dataoecd/46/14/3369 4881.pdf.

Steen, L.A. (2001). The Case for Quantitative Literacy. In L.A. Steen (Ed.), Mathematics and Democracy, The Case for Quantitative Literacy (pp. 93-98). USA: The National Council on Education and the Disciplines.

Usiskin, Z. (2001). Quantitative Literacy for the Next Generation. In L.A. Steen (Ed.), Mathematics and Democracy, The Case for Quantitative Literacy (pp. 79-86). USA: The National Council on Education and the Disciplines.

Wenger, E. (1998). Communities of Practice: Learning, Meaning and Identity. New York: Cambridge University Press.

Mathematics is not only real, but it is the only reality. That is that entire universe is made of matter, obviously. And matter is made of particles. It's made of electrons and neutrons and protons. So the entire universe is made out of particles. Now what are the particles made out of? They're not made out of anything. The only thing you can say about the reality of an electron is to cite its mathematical properties. So there's a sense in which matter has completely dissolved and what is left is just a mathematical structure. 